\title{
Clinical Significance of the HHLA2 Protein in Hepatocellular Carcinoma and the Tumor Microenvironment [Corrigendum]
}

Luo M, Lin Y, Liang R, Li Y, Ge L. J Inflamm Res. 2021;14:4217-4228.

Page 4222, Correlation Between Tumor Microenvironment and Prognosis in HCC section, the text "Based on Teng et $\mathrm{al}^{29}$ we defined four types of tumor microenvironment: type I ("adaptive immune resistance”, HHLA2 - high TILs +), which lacked HHLA2 and show intermediate or high TIL density, was observed in 77 of the 202 HCC tissues (38.1\%); type II ("immunologic ignorance", HHLA2 - low TILs -), which lacked HHLA2 and showed low TIL density, was observed in 10 cases (5.0\%); type III ("intrinsic induction", HHLA2 - high TILs -), which lacked HHLA2 and showed intermediate or high TIL density, was observed in 26 cases (12.9\%); and type IV ("tolerance", HHLA2 - low TILs +), which lacked
HHLA2 and low TIL density, was observed in 89 cases (44.0\%)" should read "Based on Teng et al, ${ }^{29}$ we defined four types of tumor microenvironment: type I ("adaptive immune resistance", HHLA2 - high TILs +), which expressed high HHLA2 and showed intermediate or high TIL density, was observed in 77 of the 202 HCC tissues (38.1\%); type II ("immunologic ignorance", HHLA2 - low TILs -), which lacked HHLA2 and showed low TIL density, was observed in 10 cases (5.0\%); type III ("intrinsic induction", HHLA2 - high TILs -), which expressed high HHLA2 and showed low TIL density, was observed in 26 cases (12.9\%); and type IV ("tolerance", HHLA2 - low TILs +), which lacked HHLA2 and showed intermediate or high TIL density, was observed in 89 cases $(44.0 \%)$ )"

The authors apologize for this error.

\section{Publish your work in this journal}

The Journal of Inflammation Research is an international, peerreviewed open-access journal that welcomes laboratory and clinical findings on the molecular basis, cell biology and pharmacology of inflammation including original research, reviews, symposium reports, hypothesis formation and commentaries on: acute/chronic inflammation; mediators of inflammation; cellular processes; molecular mechanisms; pharmacology and novel anti-inflammatory drugs; clinical conditions involving inflammation. The manuscript management system is completely online and includes a very quick and fair peerreview system. Visit http://www.dovepress.com/testimonials.php to read real quotes from published authors. 